\title{
STORABILITY OF THE RESULTANT SEEDS FROM HIGHER AND NORMAL TEMPERTURE REGIMES BY ACCELERATED AGEING
}

\author{
ANIL SEBASTIAN ${ }^{1} \&$ SELVARAJU. $P^{2}$ \\ ${ }^{1}$ Research. Scholar, Tamil Nadu Agricultural University, Coimbatore, Tamil Nadu, India \\ ${ }^{2}$ Special Officer (Seeds), Seed Centre, Tamil Nadu Agricultural University, Coimbatore, Tamil Nadu, India

\begin{abstract}
Our various initiatives to transgress the yield barriers are impeded, by high temperature stress. Being grown in narrow temperature range, a slight increase in the temperature will drastically reduce the yield of rice. Studies have been conducted on the influence of high temperature on reproductive phase and seed yield of rice. Storability due to difference in temperature of production area is less explored. Hence, the present investigation was carried out by harvesting five rice varieties viz., MDU 5, ASD 16, CO 51, Anna (R) 4 and ADT 43 from two temperature regimes-high (summer, 2016) and normal (rabi, 2016) and by subjecting the seeds to accelerated ageing. There was significant influence of temperature on germination and seedling vigour. The physiological quality parameters along with the enzyme activities were reduced rapidly, with the advance in ageing period. The rate of deterioration was more in seeds obtained from higher temperature regime.
\end{abstract}

KEYWORDS: Rice, Temperature Stress, Seed Quality, Germination \& Accelerated Ageing

Received: Oct 28, 2017; Accepted: Nov 17, 2017; Published: Dec 14, 2017; Paper Id.: IJASRDEC201754

\section{INTRODUCTION}

Globally, rice (Oryza sativa L.) is the single most important food crop in terms of direct human food consumption which is cultivated under a wide range of environments, many of which are experiencing increases in daytime and night time temperatures. Asian rice consumption is projected to account for 67 per cent of the total increase, rising from 388 million tons in 2010 to 465 million tonnes in 2035 despite a continuing decline in per capita consumption in China and India. In India, rice is grown in an area of 43.2 million hectares with a production of 104 million tonnes and productivity of 2.4 tons / ha during 2015-16 (Anonymous, 2017). Although, rice has been used as a model plant for many years, the growth responses of rice to high temperature are still poorly understood.

Seeds deteriorate during storage. This ageing is manifested as reduced percentage germination, while those seeds that do germinate, produce weak seedlings. During the ageing process, seeds lose their vigor, ability to germinate and ultimately become less viable (Maity et al., 2000). It is assumed that, as the production environment changes, the spectrum and type of infection by the pathogens, tend to change which ultimately causes severe losses during storage and also reduces the seed quality. Losses in seed quality during storage are exacerbated, if seeds are obtained from parent plants exposed to high temperature environment. There is paucity of literature on the storability of the resultant seeds from parent plant raised at higher temperatures. Hence, studies were conducted to assess the impact of high temperature of the production environment on seed storability. 


\section{MATERIALS AND METHODS}

Genetically pure seeds of rice varieties MDU 5, ASD 16, CO 51, Anna (R) 4 and ADT 43 obtained from the Department of Rice, Tamil Nadu Agricultural University, Coimbatore were used for this study during the experimental period. The field experiment was carried out at Coimbatore during summer, 2016 and during rabi, 2016. The average max. air temperature at flowering during summer, 2016 was $37^{\circ} \mathrm{C}$ and that during rabi, 2016 was $32^{\circ} \mathrm{C}$. The harvested seeds were kept for accelerated ageing for 18 days $\left(100 \%\right.$ RH, $\left.40 \pm 1^{\circ} \mathrm{C}\right)$ (Delouche and Baskin, 1973). The following observations were taken after during every 3 days interval.

\section{Germination}

The germination test was conducted by following the procedure outlined in ISTA (1999) using paper (between papers) medium. Four replicates of 100 seeds each were germinated in a germination room maintained at $25 \pm 2^{\circ} \mathrm{C}$ temperature and $95 \pm 3 \% \mathrm{RH}$. At the end of fourteenth day of sowing, the number of normal seedlings in each replication was counted and expressed in percentage.

\section{Vigour Index}

Vigour index values were computed using the following formulae and the mean values were expressed (AbdulBaki and Anderson, 1973).

Vigour index I = Germination $(\%) \mathrm{x}$ Seedling length $(\mathrm{cm})$

$\alpha$-amylase enzyme activity

Accurately $500 \mathrm{mg}$ of pre germinated seed samples were homogenized in $1.8 \mathrm{ml}$ of cold $0.02 \mathrm{M}$ sodium phosphate buffer (pH 6.0) and centrifuged at 20,000 rpm for $20 \mathrm{~min}$. to extract enzymes. To $0.1 \mathrm{ml}$ of enzyme extract, one $\mathrm{ml} 0.067$ per cent starch solution was added. The reaction was stopped after $10 \mathrm{~min}$. of incubation at $25^{\circ} \mathrm{C}$ by the addition of one $\mathrm{ml}$ of iodine $\mathrm{HCl}$ solution (60 mg KI and $6 \mathrm{mg} \mathrm{I} 2 \mathrm{in} 100 \mathrm{ml}$ of $0.05 \mathrm{~N} \mathrm{HCl}$ ). Change in color was measured at $620 \mathrm{~nm}$. The activity was calculated and expressed as mg maltose min-1 (Paul et al., 1970).

" $\alpha$ - amylase enzyme activity = " "OD value" /"Volume of sample pipetted out" " × " "1000" /"500"

\section{Dehydrogenase Activity}

For estimating the dehydrogenase activity, $0.5 \% 2,3,5$-triphenyl tetrazolium chloride solution was dissolved in Sorenson's buffer. Representative seeds from each treatment were taken and preconditioned by soaking in water for $7 \mathrm{~h}$. Seeds were bisected longitudinally into two halves, one half with embryo was steeped in tetrazolium solution and kept in dark for $2 \mathrm{~h}$ at $40^{\circ} \mathrm{C}$ for staining. After staining, the excess solution was drained and the seeds were washed thoroughly with distilled water and transferred to a test tube containing $10 \mathrm{ml}$ of 2-methoxy ethanol (methyl cello solve). The test tube was closed air tight and allowed to remain in the incubator in darkness overnight for extracting the red color formazon. The colored solution was decanted and the colour intensity was measured in an ELICO UV-VIS spectrophotometer (Model SP2205), using blue filter $(470 \mathrm{~nm})$ and methyl cellosolve as the blank. The OD value obtained was reported as dehydrogenase activity (Kittock and Law, 1968). 


\section{RESULTS}

Seed germination per cent differed significantly due to temperature, varieties, accelerated ageing and their interaction. Among the varieties, highest mean germination was recorded in Anna (R) 4 (86 \%) followed by ASD 16 (83 $\%)$. At higher temperature germination was significantly lower (74 \%) compared to normal temperature ( $84 \%)$. There was a significant decline in mean seed germination of all the varieties to 54 per cent upon accelerated ageing from 96 per cent (Initial). Among the interactions, only the interaction between temperature and varieties as well as between temperature and ageing period were found to be significant (Table 1).

For seedling vigour index, lowest seedling vigour index was recorded in CO 51 (1854). There was a drastic reduction in mean seedling vigour index, to 1397 upon accelerated ageing from 2868 (initial), irrespective of varieties. Temperature shift from normal to higher temperature caused significant change in seedling vigour index, from 2480 to 1922 (Table 2). Temperature, varieties, ageing and their interactions significantly influenced the alpha amylase activity. Alpha amylase activity was significantly higher at normal temperature (1.96) and lower at higher temperature (1.77). Anna (R) 4 recorded significantly higher amylase activity (1.98) than other varieties followed by ASD 16 (1.91). Significantly lower amylase activity was recorded in ADT 43 (1.78) which was on par with CO 51 (1.79). With the advance in ageing, the amylase activity was higher initially (2.15) and it decreased gradually and finally recorded a significantly lower value of 1.59 at the end of ageing. All the interactions were found to influence the amylase activity. For the interaction between temperature and ageing, the significantly highest effect was seen in resultant seeds from normal temperature before ageing (2.18) and lowest value was recorded in resultant seeds from higher temperature after 18 days of ageing (1.50) (Table 3). Influence of temperature, varieties and ageing along with their interactions on dehydrogenase activity is presented in Table 4. Due to higher temperature, dehydrogenase activity was significantly reduced to 0.377 from 0.529 (normal temperature). Among the varieties, Anna (R) 4 recorded significantly higher dehydrogenase activity (0.629), followed by ASD 16 (0.469) and significantly lowest value was observed in ADT 43 (0.347). With the advance in ageing period, dehydrogenase activity was found to reduce from the initial value of 0.501 . Significantly lowest dehydrogenase activity was observed 18 days, after accelerated ageing (0.411).

\section{DISCUSSIONS}

The production environment has a greater influence on the quality of the seeds produced. Dynamic nature of the production environment causes variation in seed quality also.

For high-quality seed lots, germination is desired by the seed industry to be as close to $100 \%$ as possible. The germination of a seed lot can be negatively affected by the conditions the seeds are exposed to during harvesting, drying, cleaning and storage, but can also be reduced by unfavorable environmental conditions in the field during seed growth and development (Dornbos 1995), particularly temperature, rainfall and relative humidity (Egli et al. 2005). It is generally seen that reduction in germinability, depends on quality or duration of ageing. Heat stress during seed development may result in reduced germination and loss of vigour, leading to reduced emergence and seedling establishment as observed in rice, maize, sorghum (Akman, 2009).

High-temperature stress before the developing seeds achieve physiological or mass maturity is likely to inhibit the ability of the plant to supply the seeds, with the assimilates necessary to synthesize the storage compounds required during the germination process (Dornbos, 1995), and/or the seeds suffer physiological damage to the extent that, the ability to 
germinate is lost. High-temperature stress after physiological maturity can also sometimes reduce germination but more often reduces seed vigour. In the increased temperature regime, $\mathrm{C} / \mathrm{N}$ ratio may change and it can lead to a decrease in seed protein content, resulting in a reduction in the ability of the seed to supply the amino acids required for the de novo protein synthesis necessary for embryo growth in the germinating seed. The damaging effect of high temperature stress for seed quality development is greater the earlier it is imposed after anthesis.

Alpha amylase activity is positively correlated with germination. Accelerated ageing of the resultant seeds from higher temperature regime at Coimbatore exhibited higher per cent reduction in alpha amylase activity ( $29 \%$ compared to $22 \%$ at normal temperature). If heat stress leads to mitochondrial dysfunction and membrane damage, it may also result in reduced enzyme activity (e.g. decreased $\alpha$-amylase). A-amylase actually represents the predominant contribution of the carbohydrate metabolism in endosperm of rice seeds and represents the variable spectrum of germination potential (seed vigour) of sindh rice cultivars (Galani et al., 2011). $\alpha$-amylase activity is a biochemical indicator showing different germination abilities of rice varieties, leading to different seed vigour. This finding is in accordance with the finding of Ramanadane and Ponnuswamy (2004).

Changes in germination and seedling length influence the seedling vigour. Seedling vigour compared to the initial was higher after 2 months of storage irrespective of the temperature regimes and locations. Influence of high temperature was more pronounced on seed vigour than on germination of seed. The effect of temperature on seed could either represent the cumulative effect of stress throughout seed filling, or only at maturity (Egli et al., 2005).

When the seeds were subjected artificial ageing, the reduction observed in seeds from normal temperature after 18 days of ageing was $13 \%$. The decline in dehydrogenase activity, leads to lower energy (ATP) supply to the germinating seed. Dey and Basu (1982) in sunflower reported a sharp fall in dehydrogenase activity with ageing and found that, direct correlation exists between germinability and dehydrogenase activity of seeds.

\section{CONCLUSIONS}

From the above results, it can be concluded that high temperature stress negatively influence the crop phenology. At the same time, it was observed that seed quality and storability also reduce due to high temperature stress of the parent plant production area. Anna (R) 4 maintained the seed quality even after 18 days of accelerated ageing.

\section{REFERENCES}

1. Anonymous (2017). Commodity Profile of Rice - March (2017). Retrieved from www.agricoop.nic.in

2. Maity, S., Banerjee, G., Roy, M., Pal, C., Pal, B., Chakrabarti, D. \& Bhattacharjee, A. (2000). Chemical induced prolongation of seed viability and stress tolerance capacity of mung bean seedlings. Seed Sci Technol., 28,155-162.

3. Delouche, J.C. \& Baskin, C.C. (1973). Accelerated aging techniques for predicting the relative storability seed lots. Seed Science and Technology, 1, 427-252.

4. D. M. Dangar et al.,, Effect of Irrigation Regimes and Lateral Spacing on Drip Irrigated Wheat, International Journal of Agricultural Science and Research (IJASR), Volume 7, Issue 1, January - February 2017, pp. 417-422

5. Abdul-Baki, A. A., and Anderson, J. D. 1973. Vigour deterioration of soybean seeds by multiple criteria. Crop Sci. 13, 630633.

6. Dey, G., and Basu, R.N. 1982. Studies on maintenance of seed viability of sunflower (Helianthus annuus L.) by physico- 
chemical treatments. Indian Journal of Plant Physiology. 25(1): 87-97.

7. Paul, A. K., S. MukhErji and S. M. Sircar. 1970. Metabolic changes in rice seeds during predisposition of seedling disease. Pl. Dis. Reptr., 42: 582.

8. ISTA. 1999. International rules for seed testing. International Seed Testing Association, Bassersdorf, Switzerland.

9. Kittock, P. A., and Law, A. G.1968, Relationship of seedling vigour to respiration and tetrazolium chloride reduction of germinating wheat seeds. Agron. J. 60, 286-288.

10. Ramanadane, T., and Ponnuswamy, A. S. 2004. Ageing and anatomical influence on seed storability in rice (Oryza sativa L.) hybrids and parental lines. Tropical Agricultural Research. 16, 37-50.

11. Galani, S., A. Aman and S. A. U. Qader.2011.Germination potential index of Sindh rice cultivars on biochemical basis, using amylase as an indicator.African Journal of Biotechnology, 10(80), 18334-18338.

12. Dornbos, D. L. Jr (1995). Production environment and seed quality. In Seed Quality: Basic Mechanisms and Agricultural Implications (Ed. A. S. Basra), pp. 119-152. New York: Food Products Press.

13. EGLI, D. B., TE KRONY, D. M., HEITHOLT, J. J. \& RUPE, J. (2005). Air temperature during seed filling and soybean seed germination and vigour. Crop Science 45, 1329-1335.

14. AKMAN, Z. (2009). Comparison of high temperature tolerance in maize, rice and sorghum seeds, by plant growth regulators. Journal of Animal and Veterinary Advances 8, 358-361.

15. Moreno-Martinez, E., Vazquez-Badillo, M.E., Navarrete, $R$ and Ramirez- Gonzalez, J. 1994. Effect of fungi and chemical treatment on viability of maize and barley seeds with different storage characteristics. Journal of Seed Science and Technology. 22: 541-549.

Table 1: Influence of Accelerated Ageing on Germination per cent (\%) of Resultant Rice Seeds from Normal and Higher Temperature

\begin{tabular}{|c|c|c|c|c|c|c|c|c|c|}
\hline \multirow{2}{*}{ Temperature } & \multirow{2}{*}{$\begin{array}{c}\text { Varietyd } \\
\text { (V)o }\end{array}$} & \multicolumn{8}{|c|}{ Accelerated $\cdot$ Ageing $\cdot$ Period $\cdot($ Days $) \cdot($ A) } \\
\hline & & 0 & 30 & 60 & \begin{tabular}{|c|}
90 \\
\end{tabular} & 120 & $15 \propto$ & 180 & Meano \\
\hline \multirow{6}{*}{ T1a } & $\mathrm{V1o}$ & $95 \cdot(77.08) \mathrm{d}$ & $93 \cdot(74.66) \mathrm{a}$ & $89 \cdot(70.63) a$ & $84 \cdot(66.42) \mathrm{a}$ & $78 \cdot(62.03) \mathrm{a}$ & $71 \cdot(57.42) \mathrm{a}$ & $64 \cdot(53.13) \mathrm{a}$ & $82 \cdot(64.90)$ \\
\hline & $\mathrm{V} 2 \mathrm{O}$ & $98 \cdot(81.87) \mathrm{a}$ & $96 \cdot(78.46) \mathrm{a}$ & $91 \cdot(72.54) \mathrm{a}$ & $85 \cdot(67.22) \mathrm{a}$ & $81 \cdot(64.90) \mathrm{a}$ & $73 \cdot(58.70) \mathrm{a}$ & $66 \cdot(54.33) \mathrm{a}$ & $84 \cdot(66.42)$ \\
\hline & $\mathrm{V3} \mathrm{a}$ & $97 \cdot(80.03) \mathrm{d}$ & $95 \cdot(77.08) \mathrm{a}$ & $92 \cdot(73.57) \mathrm{a}$ & $88 \cdot(69.73) \mathrm{a}$ & $83 \cdot(65.65) \mathrm{a}$ & $76 \cdot(60.67) \mathrm{a}$ & $70 \cdot(56.79) \mathrm{a}$ & $86 \cdot(68.03)$ \\
\hline & $\mathrm{V4} \mathrm{a}$ & $97 \cdot(80.03) \alpha$ & $95 \cdot(77.08) \mathrm{a}$ & $93 \cdot(74.66) a$ & $89 \cdot(70.63) \propto$ & $84 \cdot(66.42) a$ & $77 \cdot(61.34) \mathrm{a}$ & $70 \cdot(56.79) \mathrm{a}$ & $86 \cdot(68.03)$ \\
\hline & $\mathrm{V5} a$ & $94 \cdot(75.82) \mathrm{a}$ & $93 \cdot(74.66) \mathrm{a}$ & $88 \cdot(69.73) a$ & $83 \cdot(65.65) \mathrm{a}$ & $76 \cdot(60.67) a$ & $70 \cdot(56.79) a$ & $60 \cdot(50.77) \mathrm{a}$ & $81 \cdot(64.16)$ \\
\hline & Meano & $96 \cdot(78.46)$ & $94 \cdot(75.82)$ & $91 \cdot(72.54)$ & $86 \cdot(68.03)$ & $80 \cdot(63.44)$ & $73 \cdot(58.70)$ & $66 \cdot(54.33)$ & $84 \cdot(66.42)$ \\
\hline \multirow{6}{*}{$\mathbf{T} 20$} & $\mathrm{V1a}$ & $97 \cdot(80.03) \alpha$ & $91 \cdot(72.54) \mathrm{a}$ & $86 \cdot(68.03) a$ & $79 \cdot(62.73) \mathrm{a}$ & $68 \cdot(55.55) \mathrm{a}$ & $57 \cdot(49.03) a$ & $40 \cdot(39.23) a$ & $74 \cdot(59.34)$ \\
\hline & $\mathrm{V} 2 \mathrm{a}$ & $96 \cdot(78.46) \alpha$ & $92 \cdot(73.57) \mathrm{a}$ & $87 \cdot(68.87) \mathrm{a}$ & $80 \cdot(63.44) \mathrm{a}$ & $70 \cdot(56.79) \mathrm{a}$ & $60 \cdot(50.77) \mathrm{a}$ & $42 \cdot(40.40) \mathrm{a}$ & $75 \cdot(60.00)$ \\
\hline & $\mathrm{V3} a$ & $95 \cdot(77.08) \mathrm{d}$ & $89 \cdot(70.63) \mathrm{a}$ & $83 \cdot(65.65) a$ & $76 \cdot(60.67) \mathrm{a}$ & $62 \cdot(51.94) \mathrm{d}$ & $51 \cdot(45.57) \mathrm{a}$ & $38 \cdot(38.06) \mathrm{a}$ & $71 \cdot(57.42)$ \\
\hline & $\mathrm{V4} a$ & $98 \cdot(81.87) \mathrm{d}$ & $94 \cdot(75.82) \mathrm{a}$ & $88 \cdot(69.73) a$ & $82 \cdot(64.90) a$ & $72 \cdot(58.05)$ a & $61 \cdot(51.36) \mathrm{a}$ & $49 \cdot(44.43) \mathrm{a}$ & $78 \cdot(62.03)$ \\
\hline & $\mathrm{V5} a$ & $96 \cdot(78.46) \mathrm{d}$ & $91 \cdot(72.54) \mathrm{a}$ & $86 \cdot(68.03) \mathrm{a}$ & $79 \cdot(62.73) \mathrm{a}$ & $66 \cdot(54.33) \mathrm{a}$ & $52 \cdot(46.15) \mathrm{a}$ & $41 \cdot(39.82) \mathrm{a}$ & $73 \cdot(58.70)$ \\
\hline & Meano & $96 \cdot(78.46)$ & $91 \cdot(72.54)$ & $86 \cdot(68.03)$ & $79 \cdot(62.73)$ & $68 \cdot(55.55)$ & $56 \cdot(48.45)$ & $42 \cdot(40.40)$ & $74 \cdot(59.34)$ \\
\hline \multicolumn{2}{|c|}{ Grand·Meano } & $96 \cdot(78.46)$ & $93 \cdot(74.66)$ & $88 \cdot(69.73)$ & $83 \cdot(65.65)$ & $74 \cdot(59.34)$ & $65 \cdot(53.73)$ & $54 \cdot(47.30)$ & $79 \cdot(62.73)$ \\
\hline
\end{tabular}

\begin{tabular}{|c|l|l|l|l|l|l|l|}
\hline & \multicolumn{1}{|c|}{ T1 } & \multicolumn{1}{c|}{ T2 } & \multicolumn{1}{c|}{ V1 } & \multicolumn{1}{c|}{ V2 } & \multicolumn{1}{c|}{ V3 } & \multicolumn{1}{c|}{ V4 } & \multicolumn{1}{c|}{ V5 } \\
\hline Mean & $84(66.42)$ & $74(59.34)$ & $81(64.16)$ & $83(65.65)$ & $85(67.22)$ & $86(68.03)$ & $80(63.44)$ \\
\hline & T & V & A & TV & VA & TA & TVA \\
\hline SEd & $\mathbf{0 . 2 2}$ & $\mathbf{0 . 3 4}$ & $\mathbf{0 . 4 1}$ & $\mathbf{0 . 4 8}$ & $\mathbf{0 . 9 1}$ & $\mathbf{0 . 5 7}$ & $\mathbf{1 . 2 8}$ \\
\hline CD $(\mathbf{P = 0 . 0 5})$ & $\mathbf{0 . 4 3}$ & $\mathbf{0 . 6 7}$ & $\mathbf{0 . 7 9}$ & $\mathbf{0 . 9 5}$ & NS & $\mathbf{1 . 1 3}$ & NS \\
\hline
\end{tabular}

T1- Normal Temperature T2- Higher Temperature

V1-MDU 5 V2-ASD 16 V3-CO 51 V4-Anna (R) 4 V5-ADT 43
(Figures in parenthesis indicates transformed arc sine values) 
Table 2: Influence of Accelerated Ageing on Seedling Vigour Index of Resultant Rice Seeds from Normal and Higher Temperature

\begin{tabular}{|c|c|c|c|c|c|c|c|c|c|}
\hline \multirow{2}{*}{ Temperature } & \multirow{2}{*}{$\begin{array}{c}\text { Variety } \\
\text { (V) }\end{array}$} & \multicolumn{8}{|c|}{ Accelerated Ageing Period (Days) (A) } \\
\hline & & 0 & 3 & 6 & 9 & 12 & 15 & 18 & Mean \\
\hline \multirow{6}{*}{ T1 } & V1 & 2970 & 2840 & 2664 & 2449 & 2213 & 1972 & 1739 & 2407 \\
\hline & V2 & 3200 & 3069 & 2862 & 2604 & 2437 & 2146 & 1898 & 2602 \\
\hline & V3 & 2674 & 2527 & 2365 & 2215 & 2032 & 1814 & 1606 & 2176 \\
\hline & V4 & 3394 & 3241 & 3091 & 2897 & 2686 & 2424 & 2160 & 2842 \\
\hline & V5 & 2972 & 2855 & 2631 & 2425 & 2169 & 1935 & 1616 & 2372 \\
\hline & Mean & 3042 & 2906 & 2722 & 2518 & 2307 & 2058 & 1804 & 2480 \\
\hline \multirow{6}{*}{$\mathbf{T} 2$} & V1 & 2764 & 2476 & 2293 & 2065 & 1715 & 1388 & 948 & 1950 \\
\hline & V2 & 2903 & 2659 & 2458 & 2229 & 1894 & 1586 & 1070 & 2114 \\
\hline & V3 & 2250 & 1993 & 1799 & 1614 & 1289 & 1037 & 742 & 1532 \\
\hline & V4 & 2949 & 2730 & 2494 & 2304 & 1961 & 1635 & 1271 & 2192 \\
\hline & V5 & 2602 & 2345 & 2158 & 1941 & 1570 & 1212 & 923 & 1821 \\
\hline & Mean & 2694 & 2440 & 2240 & 2031 & 1686 & 1371 & 991 & 1922 \\
\hline \multicolumn{2}{|c|}{ Grand Mean } & 2868 & 2673 & 2481 & 2274 & 1997 & 1715 & 1397 & 2201 \\
\hline & & & T1 & T2 & V1 & V2 & V3 & V4 & $\mathrm{V5}$ \\
\hline \multirow{2}{*}{\multicolumn{3}{|c|}{ Mean }} & 2480 & 1922 & 2178 & 2358 & 1854 & 2517 & 2097 \\
\hline & & & $\mathbf{T}$ & $\mathbf{V}$ & $\mathbf{A}$ & TV & VA & TA & TVA \\
\hline \multicolumn{3}{|c|}{ SEd } & 7.41 & 11.71 & 13.86 & 16.56 & 30.99 & 19.59 & 43.82 \\
\hline \multicolumn{3}{|c|}{$\mathrm{CD}(\mathrm{P}=0.05)$} & 14.60 & 23.09 & 27.32 & 32.65 & 61.08 & 38.63 & $\mathrm{YS}$ \\
\hline
\end{tabular}

T1- Normal Temperature T2- Higher Temperature
V1-MDU 5
V2-ASD 16
V3-CO 51
V4-Anna (R) 4 V5-ADT 43

Table 3: Influence of Accelerated Ageing on A-Amylase Activity (mg Maltose min $^{-1}$ ) of Resultant Rice Seeds from Normal and Higher Temperature at Coimbatore

\begin{tabular}{|c|c|c|c|c|c|c|c|c|c|}
\hline \multirow{2}{*}{ Temperature } & \multirow{2}{*}{$\begin{array}{c}\text { Variety } \\
\text { (V) }\end{array}$} & \multicolumn{8}{|c|}{ Accelerated Ageing Period (Days) (A) } \\
\hline & & $\mathbf{0}$ & 3 & 6 & 9 & 12 & 15 & 18 & Mean \\
\hline \multirow{6}{*}{ T1 } & V1 & 2.15 & 2.09 & 2.01 & 1.95 & 1.84 & 1.74 & 1.64 & 1.92 \\
\hline & $\mathbf{V 2}$ & 2.19 & 2.11 & 2.04 & 1.95 & 1.86 & 1.77 & 1.65 & 1.94 \\
\hline & V3 & 2.23 & 2.15 & 2.08 & 2.01 & 1.96 & 1.87 & 1.76 & 2.01 \\
\hline & V4 & 2.24 & 2.17 & 2.11 & 2.04 & 1.97 & 1.89 & 1.77 & 2.03 \\
\hline & V5 & 2.11 & 2.06 & 2.00 & 1.92 & 1.82 & 1.73 & 1.61 & 1.89 \\
\hline & Mean & 2.18 & 2.12 & 2.05 & 1.97 & 1.89 & 1.80 & 1.69 & 1.96 \\
\hline \multirow{6}{*}{$\mathbf{T 2}$} & V1 & 2.13 & 1.95 & 1.83 & 1.79 & 1.70 & 1.64 & 1.56 & 1.80 \\
\hline & V2 & 2.17 & 2.06 & 1.94 & 1.87 & 1.78 & 1.70 & 1.60 & 1.87 \\
\hline & V3 & 1.95 & 1.72 & 1.64 & 1.56 & 1.47 & 1.35 & 1.28 & 1.57 \\
\hline & V4 & 2.21 & 2.11 & 2.01 & 1.91 & 1.82 & 1.77 & 1.69 & 1.93 \\
\hline & V5 & 2.07 & 1.87 & 1.72 & 1.63 & 1.52 & 1.44 & 1.37 & 1.66 \\
\hline & Mean & 2.11 & 1.94 & 1.83 & 1.75 & 1.66 & 1.58 & 1.50 & 1.77 \\
\hline \multicolumn{2}{|l|}{ Grand Mean } & 2.15 & 2.03 & 1.94 & 1.86 & 1.77 & 1.69 & 1.59 & 1.86 \\
\hline
\end{tabular}

\begin{tabular}{|l|c|c|c|c|c|c|c|}
\hline & T1 & T2 & V1 & V2 & V3 & V4 & V5 \\
\hline Mean & 1.96 & 1.77 & 1.86 & 1.91 & 1.79 & 1.98 & 1.78 \\
\hline & T & V & A & TV & VA & TA & TVA \\
\hline SEd & $\mathbf{0 . 0 0 5}$ & $\mathbf{0 . 0 0 8}$ & $\mathbf{0 . 0 0 9}$ & $\mathbf{0 . 0 1 1}$ & $\mathbf{0 . 0 2 0}$ & $\mathbf{0 . 0 1 3}$ & $\mathbf{0 . 0 2 8}$ \\
\hline CD $($ P=0.05) & $\mathbf{0 . 0 0 9}$ & $\mathbf{0 . 0 1 5}$ & $\mathbf{0 . 0 1 8}$ & $\mathbf{0 . 0 2 1}$ & NS & $\mathbf{0 . 0 2 5}$ & $\mathbf{0 . 0 5 6}$ \\
\hline
\end{tabular}

T1- Normal Temperature T2- Higher Temperature
V1-MDU 5
V2-ASD 16
V3-CO 51
V4-Anna (R) 4
V5-ADT 43 
Table 4: Influence of Accelerated Ageing on Dehydrogenase Activity (OD Value) of Resultant Rice Seeds from Normal and Higher Temperature at Coimbatore

\begin{tabular}{|c|c|c|c|c|c|c|c|c|c|}
\hline \multirow{2}{*}{ Temperature } & \multirow{2}{*}{$\begin{array}{c}\text { Variety } \\
\text { (V) }\end{array}$} & \multicolumn{8}{|c|}{ Accelerated Ageing Period (Days) (A) } \\
\hline & & $\mathbf{0}$ & 3 & 6 & 9 & 12 & 15 & 18 & Mean \\
\hline \multirow{6}{*}{$\mathbf{T 1}$} & V1 & 0.491 & 0.486 & 0.472 & 0.463 & 0.452 & 0.437 & 0.418 & 0.460 \\
\hline & $\mathbf{V 2}$ & 0.526 & 0.519 & 0.506 & 0.491 & 0.475 & 0.456 & 0.437 & 0.487 \\
\hline & V3 & 0.688 & 0.680 & 0.666 & 0.653 & 0.638 & 0.627 & 0.604 & 0.651 \\
\hline & $\mathbf{V 4}$ & 0.691 & 0.686 & 0.673 & 0.662 & 0.651 & 0.634 & 0.611 & 0.658 \\
\hline & V5 & 0.425 & 0.416 & 0.404 & 0.392 & 0.377 & 0.364 & 0.351 & 0.390 \\
\hline & Mean & 0.564 & 0.557 & 0.544 & 0.532 & 0.519 & 0.504 & 0.484 & 0.529 \\
\hline \multirow{6}{*}{$\mathbf{T 2}$} & V1 & 0.481 & 0.472 & 0.421 & 0.405 & 0.389 & 0.377 & 0.369 & 0.416 \\
\hline & $\mathrm{V} 2$ & 0.523 & 0.502 & 0.472 & 0.433 & 0.424 & 0.410 & 0.395 & 0.451 \\
\hline & V3 & 0.141 & 0.131 & 0.121 & 0.110 & 0.103 & 0.098 & 0.091 & 0.114 \\
\hline & V4 & 0.673 & 0.624 & 0.602 & 0.591 & 0.580 & 0.571 & 0.561 & 0.600 \\
\hline & V5 & 0.371 & 0.328 & 0.306 & 0.291 & 0.281 & 0.277 & 0.269 & 0.303 \\
\hline & Mean & 0.438 & 0.411 & 0.384 & 0.366 & 0.355 & 0.347 & 0.337 & 0.377 \\
\hline \multicolumn{2}{|c|}{ Grand Mean } & 0.501 & 0.484 & 0.464 & 0.449 & 0.437 & 0.425 & 0.411 & 0.453 \\
\hline
\end{tabular}

\begin{tabular}{|l|c|c|c|c|c|c|c|}
\hline & T1 & T2 & V1 & V2 & V3 & V4 & V5 \\
\hline Mean & 0.529 & 0.377 & 0.438 & 0.469 & 0.382 & 0.629 & 0.347 \\
\hline & T & V & A & TV & VA & TA & TVA \\
\hline SEd & $\mathbf{0 . 0 0 1}$ & $\mathbf{0 . 0 0 2}$ & $\mathbf{0 . 0 0 2}$ & $\mathbf{0 . 0 0 2}$ & $\mathbf{0 . 0 0 4}$ & $\mathbf{0 . 0 0 3}$ & $\mathbf{0 . 0 0 6}$ \\
\hline CD $($ P=0.05 $)$ & $\mathbf{0 . 0 0 2}$ & $\mathbf{0 . 0 0 3}$ & $\mathbf{0 . 0 0 4}$ & $\mathbf{0 . 0 0 5}$ & $\mathbf{0 . 0 0 9}$ & $\mathbf{0 . 0 0 5}$ & $\mathbf{0 . 0 1 2}$ \\
\hline
\end{tabular}

T1- Normal Temperature T2- Higher Temperature

V1-MDU 5 V2-ASD $16 \quad$ V3-CO $51 \quad$ V4-Anna (R) 4 V5-ADT 43 
